\title{
Normal internal calibres of ostia of great arteries and of aortic isthmus in infants and children ${ }^{1}$
}

\author{
H. VAN MEURS-VAN WOEZIK, H. W. KLEIN, AND P. KREDIET
}

From the Department of Anatomy, Faculty of Medicine, Erasmus University, Rotterdam, The Netherlands

In order to obtain reference data, useful in paediatric cardiology and paediatric cardiovascular surgery, internal diameters of the ostia of the great arteries, of the aortic isthmus, and of the descending aorta were determined with the aid of calibrated probes in 46 necropsy specimens of normal hearts with great vessels. Age range was from 25 weeks of gestational age up to 9 years post partum. The method used proved to be as accurate as echocardiography in vivo. The data revealed linear correlations between body length and calibres of aortic and pulmonary ostia. The correlation between the calibres of the pulmonary and the aortic ostia was also a linear one with the pulmonary ostium being slightly larger than the aortic ostium. From the crosssectional areas of the aortic isthmus and of the descending aorta an isthmus index was calculated which indicates the presence (and degree) or absence of a narrowing (tubular hypoplasia) of the aortic isthmus. Results show that narrowing of the aortic isthmus is inconstantly present in infants younger than 10 weeks, whereas it is always absent in infants and children older than 10 weeks. No dependence of narrowing of the aortic isthmus on developmental age attained at birth has been found.

A previous paper (van Meurs-van Woezik and Klein, 1974) confirmed that in congenitally abnormal circulatory conditions, just as in the normal situation, the cross-sectional areas of the ostia of the heart and of the great arteries at different sites correspond to the blood flow through the relevant vessels (Krediet, 1962, 1963, 1965; May, 1968). Clinical methods of quantifying ostial calibres or valve areas (Gorlin and Gorlin, 1951; Yang et al., 1972) have been estimated to be liable to errors as great as $\mathbf{2 0}$ to $\mathbf{4 0}$ per cent (Rodrigo and Snellen, 1953). Echocardiographic measurements are an exception to this general criticism. Hitherto, however, most of such determinations have been made in older children and adults with evidence of cardiovascular disturbances. When cardiovascular surgery during childhood is considered, one needs reference data on normal infants and children. This paper presents data of such type.

\section{Subjects and method}

The material obtained at necropsy consisted of 46

${ }^{1}$ We are indebted to Prof. J. Moll for his help, to Dr. J. J. Willemse for statistical calculations, to Mr. R. van Strik (Dept. of Biostatistics) and to Mr. V. H. de Villeneuve, M.D. (Dept. of Paediatric Cardio$\operatorname{logy}$ ) for advice, and to Miss D. M. D. S. Go, M.D. (Dept. of Pathology I), for supply of material.

Received for publication 6 December 1976

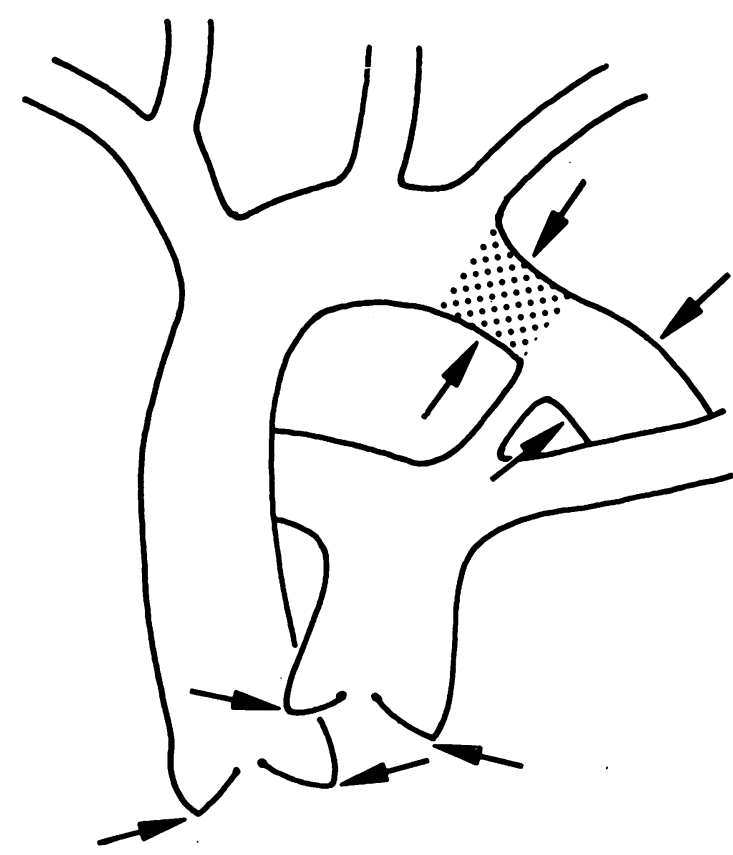

Fig. 1 Sites of measurements used (arrows); dotted area indicates aortic isthmus (for definition see 'subjects and method'). 
hearts with great vessels from babies and children or from 25 weeks of gestational age up to 9 years after birth. The sex distribution was: male 32, female 11, unknown 3 cases. All specimens were considered normal since cardiovascular abnormalities had not been diagnosed, either clinically or at necropsy. Twenty-one specimens were derived from infants and children who had been born at term, 23 from babies born prematurely, and 2 from immature babies (Table; for definition of premature and immature, see Kloosterman, 1973).

Measurements were performed as described previously on fresh material using a range of calibrated probes differing $1 \mathrm{~mm}$ in diameter (van Meurs-van Woezik and Klein, 1974). Diameter values of $0.5 \mathrm{~mm}$ were ascertained by interpolation. Measurements were carried out at various sites; those used in the present study are shown in Fig. 1. Ostia were measured at the level of the valve annulus.

The aortic isthmus was defined as the part of the aortic arch between the origin of the left subclavian artery and the mouth of the ductus arteriosus or the insertion of the ligamentum arteriosum.

Table Synopsis of data on internal calibres of ostia and arteries, body length, body weight, isthmus indices, and of grouping (see 'observations')

\begin{tabular}{|c|c|c|c|c|c|c|c|c|c|c|c|c|c|}
\hline \multirow{2}{*}{$\begin{array}{l}\text { Case } \\
\text { No. }\end{array}$} & \multirow{2}{*}{$\begin{array}{l}\text { Body } \\
\text { length } \\
(\mathrm{cm})\end{array}$} & \multirow{2}{*}{$\begin{array}{l}\text { Body } \\
\text { weight } \\
(g)\end{array}$} & \multicolumn{2}{|c|}{ Age after birth } & \multirow{2}{*}{$\begin{array}{l}\text { Gestational } \\
\text { age at birth } \\
\text { (w) }\end{array}$} & \multirow[t]{2}{*}{$\operatorname{Sex}$} & \multicolumn{2}{|c|}{$\begin{array}{l}\text { Diameter of ostium } \\
(\mathrm{mm})\end{array}$} & \multicolumn{3}{|c|}{ Diameter (mm) } & \multirow{2}{*}{$\begin{array}{l}\text { Isthmus } \\
\text { index }\end{array}$} & \multirow[t]{2}{*}{ Group } \\
\hline & & & $m$ & $d$ & & & Aorta & Pulm. & $\begin{array}{l}\text { Aortic } \\
\text { isthmus }\end{array}$ & $\begin{array}{l}\text { Aorta } \\
\text { desc. }\end{array}$ & $\begin{array}{l}\text { Ductus } \\
\text { arter. }\end{array}$ & & \\
\hline $\begin{array}{r}1 \\
2 \\
3 \\
4 \\
5 \\
6 \\
7 \\
8 \\
9 \\
10 \\
11 \\
12 \\
13 \\
14 \\
15 \\
16 \\
17 \\
18 \\
19 \\
20 \\
21 \\
22 \\
23 \\
24 \\
25 \\
26 \\
27 \\
28 \\
29 \\
30 \\
31 \\
32 \\
33 \\
34 \\
35 \\
36 \\
37 \\
38 \\
39\end{array}$ & $\begin{array}{l}30 \\
38 \\
41 \\
41 \\
42 \\
44 \\
44 \\
44 \\
44 \\
45 \\
45 \\
45 \\
45 \\
45 \\
46 \\
46 \\
46 \\
48 \\
49 \\
49 \\
50 \\
50 \\
50 \\
50 \\
51 \\
51 \\
52 \\
52 \\
53 \\
53 \\
53 \\
57 \\
57 \\
58 \\
63 \\
75 \\
74 \\
79\end{array}$ & $\begin{array}{l}1100 \\
1080 \\
1300 \\
1500 \\
1450 \\
1410 \\
1800 \\
1490 \\
1790 \\
1950 \\
1425 \\
2240 \\
1740 \\
1950 \\
2071 \\
2100 \\
1825 \\
2340 \\
3050 \\
2400 \\
2330 \\
3170 \\
1990 \\
3700 \\
2490 \\
1900 \\
2900 \\
2950 \\
3700 \\
3100 \\
3150 \\
2470 \\
3780 \\
3300 \\
6290 \\
4700 \\
7500 \\
8100 \\
9900\end{array}$ & 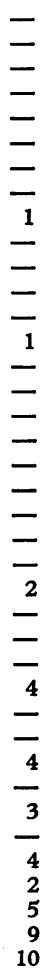 & 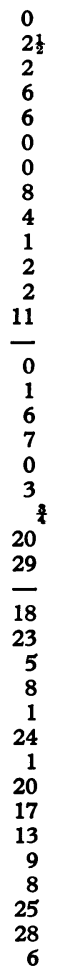 & $\begin{array}{l}25 \\
28 \\
30 \\
30 \frac{1}{2} \\
30 \\
32 \frac{1}{2} \\
33 \\
31 \\
27 \frac{1}{2} \\
31 \\
29 \\
42 \\
31 \\
\text { Prem. } \\
36 \frac{1}{2} \\
35 \frac{1}{2} \\
36 \\
32-36 \\
\text { Mat. } \\
34 \frac{1}{2} \\
34 \\
39 \\
35 \\
36 \\
\text { Prem. } \\
\text { 34 } \\
40 \\
\text { 32 } \\
\text { Mat. } \\
38 \\
\text { Mat. } \\
37 \\
\text { 32 } \\
40 \\
\text { Mat. } \\
40 \\
\text { Mat. } \\
\text { Mat. } \\
\text { Mat. }\end{array}$ & 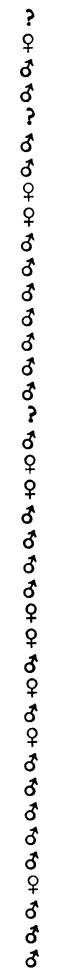 & $\begin{array}{l}4 \\
5 \\
6 \\
6 \\
6 \\
6 \\
7 \\
6 \cdot 5 \\
6 \\
6 \cdot 5 \\
5 \cdot 5 \\
6 \cdot 5 \\
6 \\
7 \\
6 \\
6 \\
5 \\
6 \cdot 5 \\
6 \cdot 5 \\
7 \\
7 \\
7 \\
7 \\
9 \\
8 \\
7 \\
7 \cdot 5 \\
7 \\
9 \\
7 \cdot 5 \\
9 \\
7 \\
8 \cdot 5 \\
8 \\
10 \\
9 \\
11 \\
10 \cdot 5 \\
12 \cdot 5\end{array}$ & $\begin{array}{l}4 \cdot 5 \\
6 \\
6 \cdot 5 \\
8 \\
7 \\
7 \cdot 5 \\
7 \\
6 \cdot 5 \\
7 \\
6 \\
5 \cdot 5 \\
7 \cdot 5 \\
6 \\
7 \\
7 \\
6 \cdot 5 \\
6 \cdot 5 \\
8 \\
7 \cdot 5 \\
7 \\
8 \\
6 \cdot 5 \\
8 \\
10 \\
10 \\
7 \cdot 5 \\
8 \\
8 \cdot 5 \\
10 \\
8 \cdot 5 \\
11 \\
8 \cdot 5 \\
9 \\
8 \cdot 5 \\
10 \cdot 5 \\
10 \\
11 \\
12 \\
15\end{array}$ & $\begin{array}{l}2 \\
3 \\
4 \cdot 5 \\
5 \\
4 \\
3 \cdot 5 \\
6 \\
4 \cdot 5 \\
3 \\
4 \\
4 \\
3 \cdot 5 \\
4 \\
4 \\
3 \cdot 5 \\
2 \cdot 5 \\
3 \\
4 \\
4 \\
4 \\
6 \\
5 \\
5 \cdot 5 \\
6 \\
6 \\
4 \cdot 5 \\
5 \\
5 \\
8 \\
5 \cdot 5 \\
7 \\
6 \\
6 \cdot 5 \\
4 \\
6 \cdot 5 \\
7\end{array}$ & 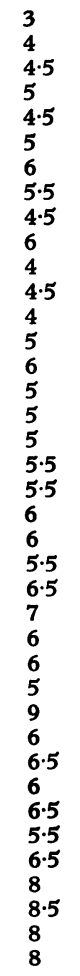 & $\begin{array}{l}2 \cdot 5 \\
2 \cdot 5 \\
2 \cdot 5 \\
4 \\
2 \\
5 \\
5 \\
2 \cdot 5 \\
0 \cdot 5 \\
4 \\
3 \\
2 \\
1 \cdot 5 \\
2 \\
4 \cdot 5 \\
4 \\
2 \\
3 \\
3 \\
4 \\
3 \\
1 \\
1 \\
2 \\
3 \\
3 \\
6 \\
0 \\
7 \\
2 \cdot 5 \\
0 \\
0 \\
0 \\
2 \\
0 \\
2 \cdot 5 \\
0 \\
0 \\
0 \\
\end{array}$ & $\begin{array}{l}0.44 \\
0.56 \\
1.00 \\
1.00 \\
0.80 \\
0.48 \\
1.00 \\
0.67 \\
0.45 \\
0.44 \\
1.00 \\
0.60 \\
1.00 \\
0.64 \\
0.33 \\
0.24 \\
0.36 \\
0.64 \\
0.53 \\
0.53 \\
1.00 \\
0.70 \\
1.00 \\
0.85 \\
0.73 \\
0.56 \\
0.70 \\
1.00 \\
0.79 \\
0.84 \\
1.17 \\
1.00 \\
1.00 \\
0.53 \\
1.00 \\
0.77 \\
1.12 \\
1.00 \\
1.13\end{array}$ & $\begin{array}{l}\text { I } \\
\text { I I } \\
\text { II } \\
\text { I } \\
\text { I } \\
\text { II } \\
\text { I } \\
\text { I } \\
\text { I } \\
\text { II } \\
\text { I } \\
\text { II } \\
\text { I } \\
\text { I } \\
\text { I } \\
\text { I } \\
\text { I } \\
\text { I } \\
\text { I } \\
\text { II } \\
\text { I } \\
\text { II } \\
\text { II } \\
\text { I } \\
\text { I } \\
\text { I } \\
\text { III } \\
\text { I } \\
\text { II } \\
\text { III } \\
\text { III } \\
\text { III } \\
\text { I } \\
\text { III } \\
\text { I } \\
\text { III } \\
\text { III } \\
\text { III }\end{array}$ \\
\hline & & & $y$ & $m$ & & & & & & & & & \\
\hline $\begin{array}{l}40 \\
41 \\
42 \\
43 \\
44 \\
45 \\
46\end{array}$ & $\begin{array}{r}90 \\
116 \\
117 \\
122 \\
122 \\
123 \\
143\end{array}$ & $\begin{array}{l}10100 \\
16000 \\
19000 \\
? \\
21000 \\
38000 \\
36000\end{array}$ & $\begin{array}{l}1 \\
3 \\
6 \\
5 \\
9 \\
5 \\
8\end{array}$ & $\begin{array}{r}11 \\
9 \\
9 \\
11 \\
11 \\
8 \\
-\end{array}$ & $\begin{array}{l}\text { Mat. } \\
\text { Mat. } \\
\text { Mat. } \\
\text { Mat. } \\
\text { Mat. } \\
\text { Mat. } \\
\text { Mat. }\end{array}$ & $\begin{array}{l}0 \\
0 \\
0 \\
0 \\
+ \\
0 \\
0 \\
0 \\
0 \\
0 \\
0\end{array}$ & $\begin{array}{l}11 \\
15 \\
15 \\
18 \\
17 \\
17 \\
16.5\end{array}$ & $\begin{array}{l}11 \\
17 \\
18 \\
19 \cdot 5 \\
22 \\
20 \\
18\end{array}$ & $\begin{array}{l}? \\
14 \\
14 \\
13 \cdot 5 \\
14 \\
12 \\
11 \cdot 5\end{array}$ & $\begin{array}{l}? \\
14 \\
13 \\
13.5 \\
14 \\
12 \\
10.5\end{array}$ & $\begin{array}{l}0 \\
0 \\
0 \\
0 \\
0 \\
0 \\
0\end{array}$ & $\begin{array}{l}? \\
1 \cdot 00 \\
1 \cdot 16 \\
1 \cdot 00 \\
1 \cdot 00 \\
1 \cdot 00 \\
1 \cdot 20\end{array}$ & $\begin{array}{l}? \\
\text { III } \\
\text { III } \\
\text { III } \\
\text { III } \\
\text { III } \\
\text { III }\end{array}$ \\
\hline
\end{tabular}




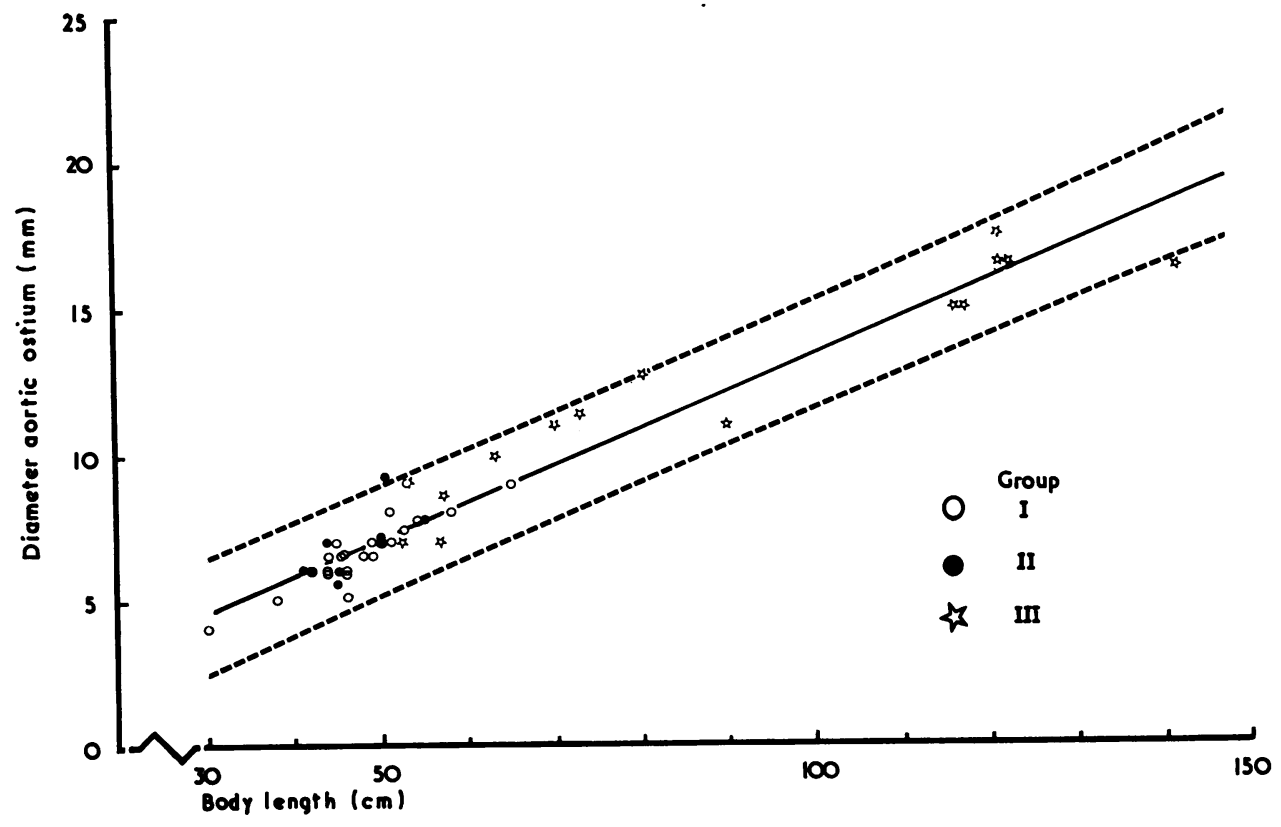

Fig. 2 Correlation between internal diameters of aortic ostium and body length; interrupted lines indicate prediction interval. For definitions of groups see 'observations' and Table.

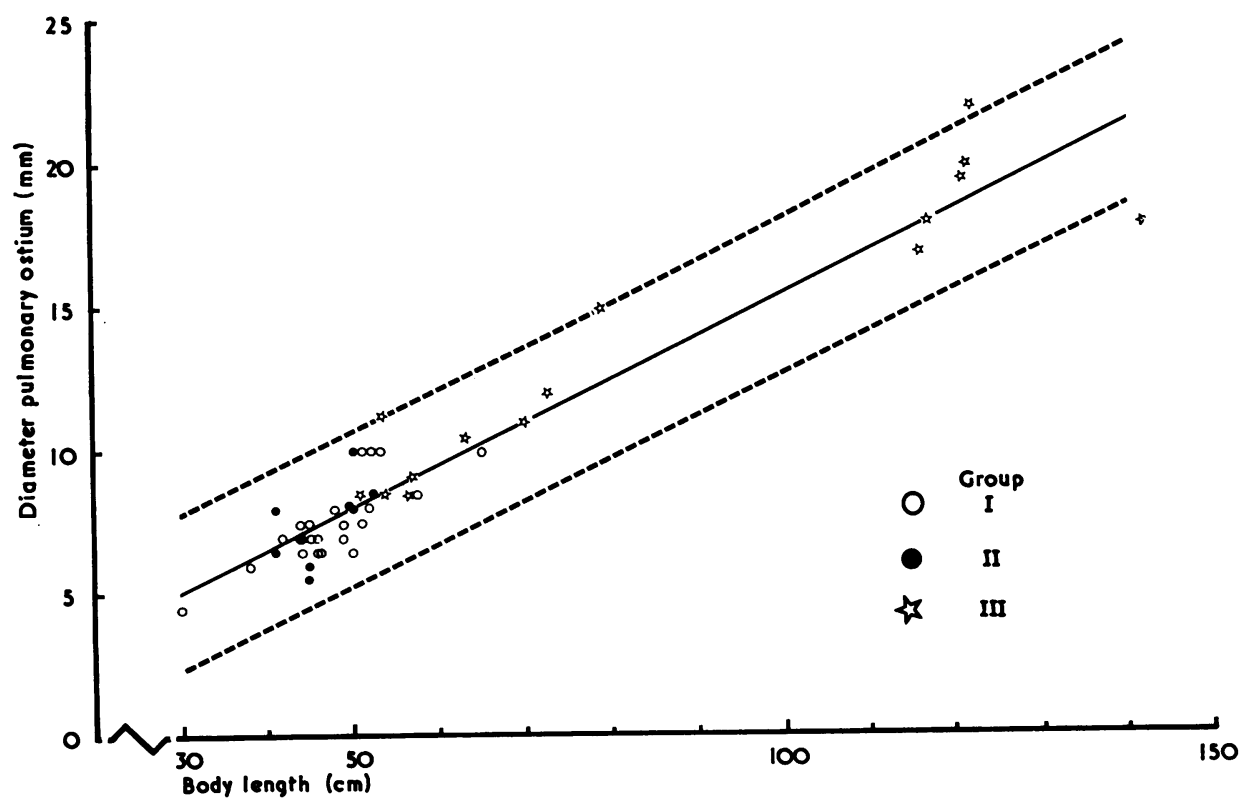

Fig. 3 Correlation between internal diameters of pulmonary ostium and body length; interrupted lines indicate prediction interval. For definitions of groups see 'observations' and Table. 


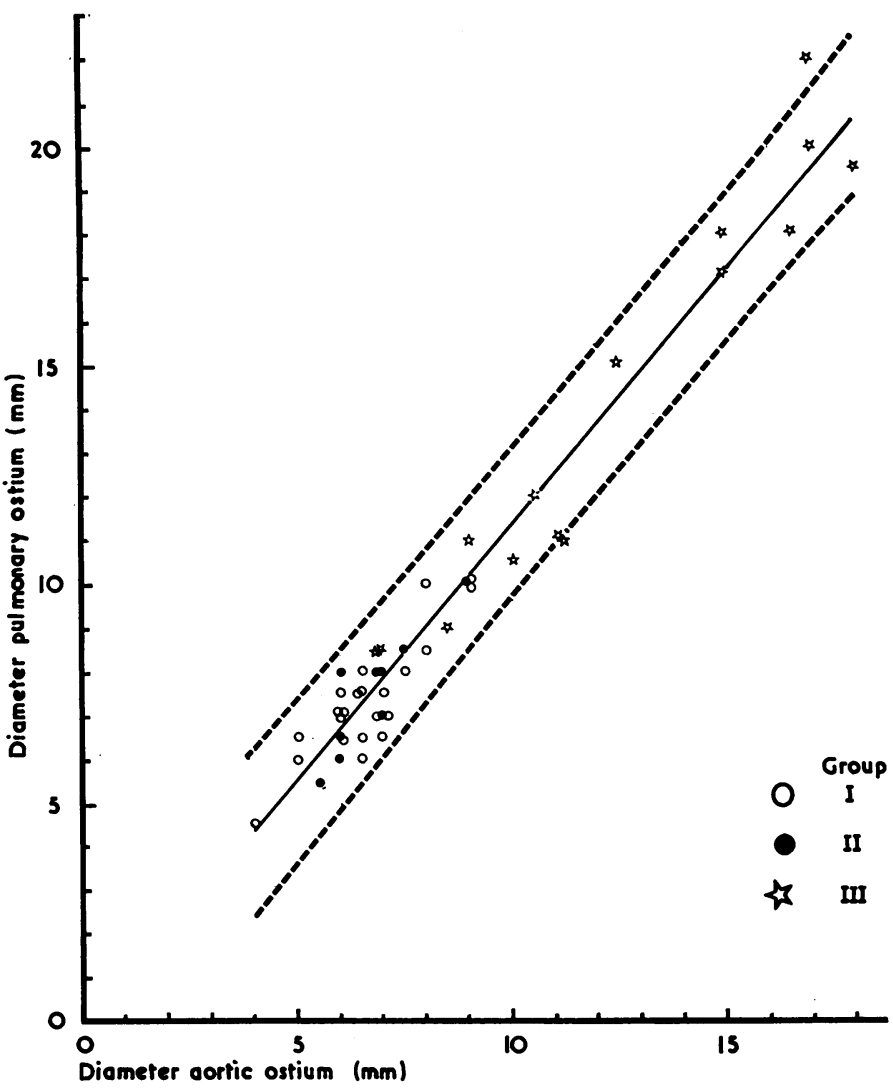

Fig. 4 Correlation between internal diameters of aortic and pulmonary ostia; interrupted lines indicate prediction interval. For definitions of groups see 'observations' and Table.
Cross-sectional areas of the ostia of the great arteries, of the aortic isthmus, and of the descending aorta were calculated as an indication of blood flow. Correlations were calculated following Sachs (1973).

\section{Observations}

In the Table the data on internal measurements of ostia and arteries, on body length, body weight, and age are summarised. In three graphs the following relations are depicted: diameters of aortic ostia versus body length (Fig. 2), diameters of pulmonary ostia versus body length (Fig. 3), diameters of pulmonary ostia versus diameters of aortic ostia (Fig. 4); prediction intervals are included. Fig. 2 and 3 show that linear correlations exist between body length and calibres of the aortic and pulmonary ostia. As expected, Fig. 4 shows a linear correlation between the diameters of both ostia with the pulmonary ostium being slightly larger than the aortic ostium (1.14:1).

For a judgement of presence or absence of a narrowing of the aortic isthmus we used the index cross-sectional area of the aortic isthmus at its narrowest site divided by cross-sectional area of the descending aorta immediately distal to the ductus arteriosus or to the ligamentum arteriosum. We then defined as follows: isthmus index $<0.81$, presence of narrowing of the aortic isthmus; isthmus index $\geq 0.81$, absence of narrowing of the aortic isthmus. The following grouping of the material was then possible.

Group I: Isthmus index $<0.81$ with ductus arteriosus patent, 22 cases (of which 13 were premature, 2 were immature); age after birth from 0 days up to 10 weeks;

Group II : Isthmus index $\geq 0.81$ with ductus arteriosus patent, 9 cases (of which 8 were premature, none was immature); age after birth from 0 days up to 2 months;

Group III : Isthmus index $\geq 0.81$ with ductus arteriosus closed, 14 cases (of which 2 were premature, none was immature); age after birth from 20 days up to 9 years.

Cases with an isthmus index $<0.81$ together with a closed ductus arteriosus did not occur. Four observations concerning the isthmus should be 
mentioned: (1) narrowing of the aortic isthmus was never present in a child older than 10 weeks; (2) of the 23 prematurely born babies, which had died very young (before 11 days after birth), 13 showed a narrowing of the aortic isthmus (Table); (3) narrowing of the aortic isthmus may be severe: out of the 45 cases, $13 \mathrm{had}$ an isthmus index $\leq 0 \cdot 60,7$ an index $\leq 0.50$ but this finding was confined to the infants less than 5 weeks old; (4) a clear correlation between isthmus index and body length was absent.

\section{Discussion}

The question dealt with in the present study has received attention over a number of decades and several approaches have been used. The sites of measuring of the ostia and arteries differ considerably in the published reports. Data on the aortic and pulmonary ostia are few, and measurements have often been made 1 to $2 \mathrm{~cm}$ beyond their valves (Beneke, 1878, 1879; Sinha et al., 1969; Rudolph et al., 1972; Bruins, 1973).

In normal cases the diameter of the annulus is as a rule smaller than the diameter of the corresponding artery beyond it, that is the ascending aorta, or pulmonary trunk (van Meurs-van Woezik and Klein, 1974). Therefore, we preferred as the sites for measurement these two ostia, the narrowest'sites of the main pathways of blood"flow through"the heart.

In previous studies the measuring techniques have sometimes not been reported or little detail has been given (de la Cruz et al., 1960; Sinha et al., 1969). In addition some measurements have been made using a ruler after slitting and flattening out of the great arteries (Beneke, 1878, 1879). Different pressure on the ruler caused changes in the results of up to $4 \mathrm{~mm}$ (Beneke, 1878), which correspond to errors much larger than those observed using our technique, for which relatively small measuring errors have been determined (van Meurs-van Woezik and Klein, 1974). Measurement after histological sectioning has also been used (Odé, 1951), but will be inaccurate because of variable shrinkage and distortion caused by fixation, embedding, and spreading. Measurements from plastic casts (Wright, 1969; Rudolph, 1970; Rudolph et al., 1972) may also not be fully reliable since we have found from personal experience that blood clots and gas bubbles may prevent correct filling by the casting material, especially at the ostia.

Clinically, echocardiography seems to be the most accurate method for measuring ostia and vessels. Our post mortem data for the pulmonary ostium correspond exactly with those obtained in vivo by Solinger et al. (1973) using echocardiography. However, their values for the aortic ostium are constantly $2 \mathrm{~mm}$ below ours, probably because measurements have not been made through the centre of this ostium, as indicated by Fig. 5 of the paper by Solinger et al. Other methods for clinical determination of calibres of ostia and great vessels seem inaccurate (Rodrigo and Snellen, 1953). Based on personal experience we have found that this also holds for angiographic methods as used by Sinha et al. (1969).

Since our study is largely concerned with growing individuals, correlation of our measurements with indices of bodily development is important. Commonly used indices of bodily development are age, body length, body weight, and body surface area. Since age is not closely related with bodily development (Tanner et al., 1966) this measure, used by de la Cruz et al. (1960) and Eckner et al. (1969), is not a good choice. Furthermore in sick children body weight can change considerably within a short time. Body surface area is usually derived in part from body weight and is, therefore, also a measure of doubtful value. The most useful measure seems to be body length since it is not affected by short term changes caused by ill health. In consequence, we compared our measurements with body length. The echocardiographic data of Solinger et al. (1973), recalculated using the table by van Wieringen (1973) for converting body weight to body length, correspond, as mentioned, exactly to our data for the pulmonary ostium.

The data revealed linear correlations between body length and the diameters of aortic and pulmonary ostia. This is plausible because of the linear correlation between body surface, metabolism, and blood flow on the one hand and cross-sectional areas of the great vessels on the other hand.

Since the aortic isthmus with its variable calibre might act as a circulatory bottleneck and might cause clinically demonstrable differences between systolic blood pressure of the upper and lower limbs (De Swiet et al., 1974), special attention has been paid to the presence and degree of narrowing (tubular hypoplasia) of the aortic isthmus in this material of normal hearts and great vessels. Our pertinent observations require some comment. In order to ascertain the presence or absence of narrowing of the aortic isthmus the question arises as to which segment of the aorta should be compared with the aortic isthmus. In our opinion this should be the descending aorta for the following reasons: before birth the total cardiac foutput, minus the amount of blood given off to thead, neck, arms, lungs, and-in part-to the coronary arteries, reassembles in the descending aorta. After birth, when the ductus arteriosus has closed, all blood passing the aorta ostium, minus blood to head, neck, arms and-in part-to the coronary arteries, 
will pass via the aortic isthmus also into the descending aorta. Furthermore, since during fetal life calibres of both ascending aorta and aortic isthmus are influenced by the size of the aortic ostium, it seems less appropriate for our purpose to follow Sinha et al. (1969) and to compare the aortic isthmus not only with the descending aorta but also with the ascending aorta.

An internal diameter of the aortic isthmus 10 per cent less than that of the descending aorta has been chosen arbitrarily as indicative of narrowing (tubular hypoplasia). Expressed in cross-sectional areas this leads to a borderline value of 0.81 for the isthmus index (see 'subjects and method').

From our observations on normal hearts and great arteries the following conclusions on the aortic isthmus can be drawn.

(1) Under normal conditions narrowing of the aortic isthmus (isthmus index $\leq 0.81$ ) may or may not exist in babies younger than 10 weeks, both in those born at term and pre- or immaturely, whereas in babies older than 10 weeks, born at term, pre-, or immaturely, narrowing of the aortic isthmus cannot be expected.

(2) In the babies younger than 5 weeks pronounced narrowing was not exceptional.

(3) No dependence of narrowing of the aortic isthmus on developmental age attained at birth seems to exist.

In conclusion it should be stressed that these observations, both those on calibres of the aortic and pulmonary ostia and those on the aortic isthmus, characterise quantitative aspects of the normal vasculature. The definition of borderline values between normal and pathological conditions is a desirable next step which we have not yet attempted. However, the data reported provide a necessary starting point for defining such borderline values.

\section{References}

Beneke, F. W. (1878). Die anatomischen Grundlagen der Constitutionsanomalieen des Menschen. N. G. Elwert, Marburg (Germany).

Beneke, F. W. (1879). Ueber das Volumen des Herzens und die Weite der Arteria pulmonalis und Aorta ascendens in den verschiedenen Lebensaltern. Theodor Kay, Cassel (Germany).

Bruins, C. L. D. Ch. (1973). De arteriële pool van het hart: wisselwerking tussen bloedstroom en hart-vaatstelsel, getoetst aan enkele aangeboren hartvaatgebreken. Thesis, Leiden (The Netherlands).

de la Cruz, M. V., Anselmi, G., Romero, A., and Monroy, G. (1960). A qualitative and quantitative study of the ventricles and great vessels of normal children. American Heart fournal, 60, 675-690. de Swiet, M., Peto, J., and Shinebourne, E. A. (1974). Difference between upper and lower limb blood pressure in normal neonates using Doppler technique. Archives of Disease in Childhood, 49, 734-735.

Eckner, F. A. O., Brown, B. W., Davidson, D. L., and Glagov, S. (1969). Dimensions of normal human hearts. Archives of Pathology, 88, 497-507.

Gorlin, R., and Gorlin, S. G. (1951). Hydraulic formula for calculation of the area of the stenotic mitral valve, other cardiac valves and central circulatory shunts. American Heart fournal, 41, 1-29.

Kloosterman, G. J. (1973). De voortplanting van de mens. Centen, Bussum (The Netherlands).

Krediet, P. (1962). Anomalies of the arterial trunks in the thorax and their relation to normal development. Thesis, Utrecht (The Netherlands).

Krediet, P. (1963). Isthmus stenosis and coarctation. In Second European Anatomical Meeting, p. 88-89. International Congress Series No. 70. Excerpta Medica, Amsterdam.

Krediet, P. (1965). A hypothesis of the development of coarctation in man. Acta Morphologica Neerlando-Scandinavica, 6, 207-212.

May, N. D. S. (1968). Experimental studies of the collateral circulation in the head and neck of sheep (Ovis aries). Fournal of Anatomy, 103, 171-181.

Odé, E. (1951). De ductus arteriosus. Thesis, Leiden (The Netherlands).

Rodrigo, F. A., and Snellen, H. A. (1953). Estimation of valve area and 'valvular resistance'. A critical study of the physical basis of the method employed. American Heart Fournal, 45, 1-12.

Rudolph, A. M. (1970). The changes in the circulation after birth. Their importance in congenital heart disease. Circulation, 41, 343-359.

Rudolph, A. M., Heymann, M. A., and Spitznas, U. (1972). Hemodynamic considerations in the development of narrowing of the aorta. American fournal of Cardiology, 30, 514-525.

Sachs, L. (1973). Angewandte Statistik. Springer, Berlin, Heidelberg, and New York.

Sinha, S. N., Kardatzke, M. L., Cole, R. B., Muster, A. J., Wessel, H. U., and Paul, M. H. (1969). Coarctation of the aorta in infancy. Circulation, 40, 385-398.

Solinger, R., Elbl, F., and Minhas, K. (1973). Echocardiography in the normal neonate. Circulation, 47, 108-118.

Tanner, J. M., Whitehouse, R. H., and Takaishi, M. (1966). Standards from birth to maturity for height, weight, height velocity and weight velocity: British children, 1965. Archives of Disease in Childhood, 41, 454-471; 613-635. van Meurs-van Woezik, H., and Klein, H. W. (1974). Calibres of aorta and pulmonary artery in hypoplastic left and right heart syndromes: effects of abnormal bloodflow? Virchows Archiv Abteilung A. Pathological Anatomy and Histology, 364, 357-364.

van Wieringen, J. C. (1973). Lengte en gewicht van kinderen. Maandschrift voor Kindergeneeskunde, 41, 69-80.

Wright, N. L. (1969). Dissection study and mensuration of the human aortic arch. Fournal of Anatomy, 104, 377-385.

Yang, S. S., Bentivoglio, L. G., Maranhão, V., and Goldberg, H. (1972). From Cardiac Catheterization Data to Hemodynamic Parameters. F. A. Davis, Philadelphia.

Requests for reprints to Dr. H. W. Klein, Erasmus University, Faculty of Medicine, Department of Anatomy, P.O. Box 1738, Rotterdam, The Netherlands. 